䗆 


\section{Computational Earthquake Science Part I}

Edited by

Andrea Donnellan

Peter Mora

Mitsuhiro Matsu'ura

Xiang-chu Yin

Springer Basel AG 
Reprint from Pure and Applied Geophysics

(PAGEOPH), Volume 161 (2004), No. 9/10

Editors:

Andrea Donnellan

Earth and Space Sciences Division

Jet Propulsion Laboratory

California Institute of Technology

Pasadena, CA 91109-8099

USA

e-mail: donnellan@jpl.nasa.gov

Peter Mora

QUAKES, Earth Systems Science

Computational Centre

(ESSCC), Department of Earth Sciences

The University of Queensland

4072 Brisbane, Qld

Australia

e-mail: morap@quakes.uq.edu.au

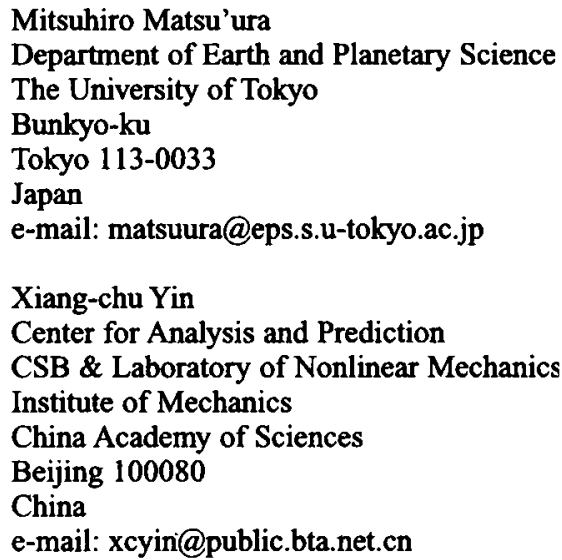

A CIP catalogue record for this book is available from the Library of Congress, Washington D.C., USA

Bibliographic information published by Die Deutsche Bibliothek:

Die Deutsche Bibliothek lists this publication in the Deutsche Nationalbibliografie;

detailed bibliographic data is available in the internet at $<\mathrm{http}: / / \mathrm{dnb} . \mathrm{ddb} . \mathrm{de}>$

ISBN 978-3-7643-7142-5

DOI $10.1007 / 978-3-0348-7873-9$

This work is subject to copyright. All rights are reserved, whether the whole or part of the material is concerned, specifically the rights of translation, reprinting, re-use of illustrations, recitation, broadcasting, reproduction on microfilms or in other ways, and storage in data banks. For any kind of use, permission of the copyright owner must be obtained.

(C) 2004 Springer Basel AG

Originally published by Birkhäuser Verlag in 2004

Printed on acid-free paper produced from chlorine-free pulp

ISBN 978-3-7643-7142-5

987654321

www.birkhauser-science.com 
Contents

1823 Introduction

A. Donnellan, P. Mora, M. Matsu'ura, X. C. Yin

A. Microscopic Simulation

1829 Statistical Tests of Load-Unload Response Ratio Signals by Lattice Solid Model: Implication to Tidal Triggering and Earthquake Prediction

Y. Wang, P. Mora, C. Yin, D. Place

1841 Long-range Stress Redistribution Resulting from Damage in Heterogeneous Media

Y. Bai, Z. Jia, X. Zhang, F. Ke, M. Xia

1853 Review of the Physical Basis of Laboratory-derived Relations for Brittle Failure and their Implications for Earthquake Occurrence and Earthquake Nucleation

N. M. Beeler

1877 Particle Dynamics Simulations of Rate- and State-dependent Frictional Sliding of Granular Fault Gouge

J. K. Morgan

B. Scaling Physics

1895 The Dependence of Constitutive Properties on Temperature and Effective Normal Stress in Seismogenic Environments

A. Kato, S. Yoshida, M. Ohnaka, H. Mochizuki

1915 A Constitutive Scaling Law for Shear Rupture that is Inherently Scaledependent, and Physical Scaling of Nucleation Time to Critical Point M. Ohnaka

1931 Critical Sensitivity in Driven Nonlinear Threshold Systems

X. Zhang, X. Xu, H. Wang, M. Xia, F. Ke, Y. Bai

1945 Intermittent Criticality and the Gutenberg-Richter Distribution D. D. Bowman, C. G. Sammis

1957 Ergodicity in Natural Fault Systems

K. F. Tiampo, J. B. Rundle, W. Klein, J. S. Sá Martins 
1969 Focal Mechanism Dependence of a Few Seismic Phenomena and its Implications for the Physics of Earthquakes

Z. L. Wu, Y. G. Wan, G. W. Zhou

1979 Continuum Fractal Mechanics of the Earth's Crust

A. V. Dyskin

1991 Using Eigenpattern Analysis to Constrain Seasonal Signals in Southern California

K. F. Tiampo, J. B. Rundle, W. Klein, Y. Ben-Zion, S. McGinnis

2005 Accelerating Precursory Activity within a Class of Earthquake Analogue Automata

D. Weatherley, P. Mora

C. Earthquake Generation and Cycles

2023 Dynamical System Analysis and Forecasting of Deformation Produced by an Earthquake Fault

M. Anghel, Y. Ben-Zion, R. Rico-Martinez

2053 3-D Modelling of Plate Interfaces and Numerical Simulation of Long-term Crustal Deformation in and around Japan

C. Hashimoto, K. Fukui, M. Matsu'ura

2069 GeoFEM Kinematic Earthquake Cycle Simulation in Southwest Japan M. Hyodo, K. Hirahara

2091 Finite Element Analysis of Fault Bend Influence on Stick-Slip Instability along an Intra-Plate Fault

H. L. Xing, P. Mora, A. Makinouchi

2103 Quasi-static and Quasi-dynamic Modeling of Earthquake Failure at Intermediate Scales

G. Zöller, M. Holschneider, Y. Ben-Zion 